This PDF is a selection from an out-of-print volume from the National Bureau of Economic Research

Volume Title: Anticipations and Purchases: An Analysis of Consumer Behavior

Volume Author/Editor: F. Thomas Juster

Volume Publisher: Princeton University Press

Volume ISBN: 0-87014-079-5

Volume URL: http://www.nber.org/books/just64-1

Publication Date: 1964

Chapter Title: Appendix B: Interrelations Among Intentions and Purchases for Individual Commodities

Chapter Author: F. Thomas Juster

Chapter URL: http://www.nber.org/chapters/c1037

Chapter pages in book: ( $264-285$ ) 


\section{APPENDIX B \\ Interrelations Among Intentions and Purchases for Individual Commodities}

\section{Introduction}

THE problem of aggregating buying intentions for individual commodities is one of the most interesting in the analysis of these data. I have touched on one facet of the aggregation problem in Chapter 4 of the text, where I pointed out that aggregation of buying intentions is by no means a perfect substitute for aggregation of purchase probabilities because the probabilities associated with the same intentions question appear to differ among commodities. Other aspects of this problem deserve attention. First, is there any evidence that the characteristics of sample households are such that buying intentions tend to be associated with different probabilities for different groups of people? Evidence already presented suggests that this is not the case for households in different income, age, or education classes, since mean probability among intenders seemed to be essentially unrelated to these characteristics. But a serious "response" bias may nevertheless exist. One group of households may systematically answer intentions questions in terms of what they "wish they could" purchase, while another group may systematically interpret these questions as asking what they are "practically certain they will do" during the specified period. If so, it would be necessary to have some means of identifying these groups, since it would otherwise be impossible to make accurate estimates of mean purchase probability from surveys of buying intentions. The evidence examined above does not preclude the possibility of systematic differences of this sort; it simply suggests that such personality differences are not related to household characteristics such as income, age, or education.

Second, is the typical pattern of purchases within the durable goods complex one of substitution, complementarity, or no association; that is, are households that purchase commodity A more likely or less likely, other things equal, to purchase other durable commodities in addition to A? This problem relates to the analysis of consumer behavior proper rather than to the analysis of survey data as a predictor of behavior. Finally, if a household reports intentions to buy $\mathrm{A}$ and does not purchase, is it more likely or less likely, other things equal, to buy commodity B?

\section{An Analysis of Response Bias}

The first and second of these problems can be analyzed by an examination of interdependence between buying intentions and purchases for indi- 
vidual commodities. If the response problem is serious, some households-perennial optimists-report a relatively large number of buying intentions but purchase neither more nor less than others with the same income, age, etc. Other households-perennial pessimists-report relatively few buying intentions but again purchase neither more nor less than others with the same economic status. The remaining households report a "normal" amount of buying intentions and make a "normal" amount of purchases. If such is the case, it can be shown that the sample as a whole will show a stronger degree of interdependence for buying intentions than for purchases. That is, those reporting intentions to buy A will be more likely, ceteris paribus, to report buying intentions for $\mathrm{B}, \mathrm{C}$, ... , or $\mathrm{N}$ than will those purchasing $\mathrm{A}$ to report the purchase of $\mathrm{B}, \mathrm{C}$, . . . , or $\mathrm{N}$ as well.

The argument follows. Assume that data are available for a sample of households with the same income and demographic status but different interpretations of the buying intentions question; further assume that $a$ per cent of the sample purchase commodity $\mathrm{A}$ and $b$ per cent purchase $\mathrm{B}$ during the forecast period, that $\hat{a}$ and $\hat{b}$ per cent of the "normal" households report buying intentions for $\mathrm{A}$ and $\mathrm{B}$, and that $a=\hat{a}, b=\hat{b}$. Finally, assume that less than $\hat{a}(\hat{b})$ per cent of the perennial pessimists report buying intentions for $\mathrm{A}(\mathrm{B})$; more than $\hat{a}(\hat{b})$ per cent of the perennial optimists report intentions to buy $A(B)$; but that both pessimists and optimists have the same purchase rates as "normal" households, i.e., equal to $a(b)$. To make the illustration concrete, it is specified that half as many pessimists and twice as many optimists report intentions as normal households, and that the three groups are of equal size. Given these assumptions, the following data would be obtained:

1. The number of households that report buying intentions for commodity $\mathrm{A}-\hat{P}_{A}-$ aggregating across the three groups, would be

$$
\begin{aligned}
\Sigma \hat{P}_{A} & =\hat{a} \frac{N}{3}+0.5 \hat{a} \frac{N}{3}+2 \hat{a} \frac{N}{3} \\
& =1.17 \hat{a} N
\end{aligned}
$$

Commodity B would show a similar pattern; hence,

$$
\Sigma \hat{P}_{B}=1.17 \hat{b} N
$$

2. The number of households reporting purchases of commodity A$P_{A}$-again aggregating across the three groups, would be:

$$
\Sigma P_{A}=a \frac{N}{3}+a \frac{N}{3}+a \frac{N}{3}=a N
$$


For commodity B, similarly

$$
\Sigma P_{B}=b N
$$

If it is now assumed that buying intentions and purchases are both completely independent among households within each of the three response groups, the observed frequency of those purchasing or intending to buy both $A$ and $B$, neither $A$ nor $B, A$ but not $B$, and $B$ but not $A$ would be the products of the respective probabilities, aggregated across groups. ${ }^{1}$ Given the above assumptions about rates of buying intentions and purchases in" the three groups, the observed frequencies would be those in the top panel of Table B-1. Testing for independence, the predicted frequencies of buying intentions or purchases for the sample as a whole work out as in the middle panel of Table B-1. The pattern predicted for the sample as a whole, in testing for independence among purchases, will be exactly the same as the observed pattern. But for buying intentions, the predicted pattern will differ from the observed pattern because of response bias.

Evidently, even complete independence between intentions to buy $\mathrm{A}$ and $B$ within the three response groups will show up as some degree of interdependence in data for the sample as a whole. In this illustration, the differences between observed frequencies (based on the assumption that each of the three groups is characterized by complete independence) and predicted frequencies (testing the hypothesis that the sample as a whole is characterized by complete independence) are those in the bottom panel of Table B-1.

The observed pattern for buying intentions is one of positive interdependence; households reporting intentions to buy A will be more likely to report $B$ intentions than others; those not reporting $A$, less likely to report $B$ than others; and so forth. And the result is wholly due to the existence of response bias, because the observed pattern was based on the assumption of complete independence for both intentions and purchases within each of the three response groups.

If response bias does exist, buying intentions will always have a greater degree of interdependence than purchases, ceteris paribus. Note that the difference between the observed and predicted frequencies has the form:

$$
\left(1.75-1.17^{2}\right) \hat{a} \hat{b} N
$$

\footnotetext{
1 For example, if $\mathrm{a}$ and $\mathrm{b}$ are the purchase rates for commodities $\mathrm{A}$ and $\mathrm{B}$, respectively, the expected number of households purchasing both $A$ and $B$ (assuming independence) is abN, the expected number purchasing neither is $(1-a)(1-b) N$, the expected number purchasing $\mathrm{A}$ but not $\mathrm{B}$ is $a(1-b) N$, and the expected number purchasing $\mathrm{B}$ but not $\mathrm{A}$ is $b(1-a) N$.
} 


\section{$A P P E N D I X \quad B$}

TABLE B-1

Illustrative Distribution of Observed and Predicted Frequency of Joint Intentions and Purchases by Households Classified as Pessimistic,

Optimistic, OR NORMAL

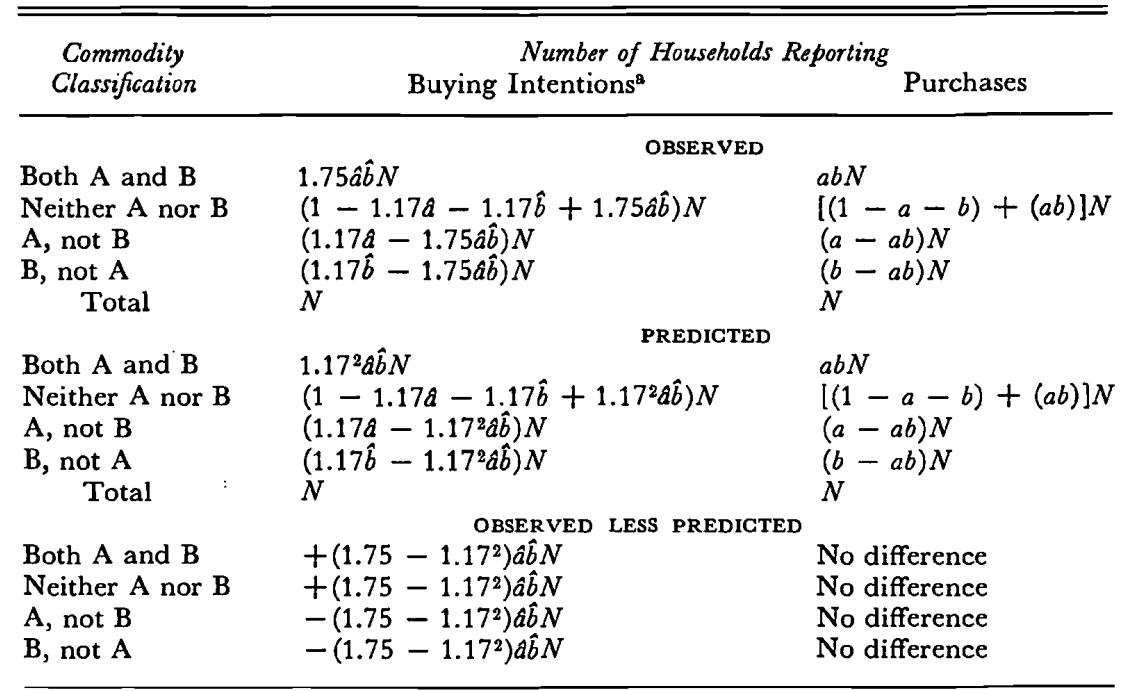

Source: Basic data from Consumer Purchase Study, NBER.

- The calculation is as follows: The assumed intentions and purchases rates for commodities $\mathrm{A}$ and $\mathrm{B}$ in the three response groups are

\begin{tabular}{lcccc} 
& Buying Intentions & \multicolumn{3}{c}{ Purchases } \\
& $\mathrm{A}$ & $\mathrm{B}$ & $\mathrm{A}$ & $\mathrm{B}$ \\
Pessimists $(N / 3)$ & $0.5 \hat{a}$ & $0.5 \hat{b}$ & $a$ & $b$ \\
Normal $(N / 3)$ & $1.0 \hat{a}$ & $1.0 \hat{b}$ & $a$ & $b$ \\
Optimists $(N / 3)$ & $2.0 \hat{d}$ & $2.0 \hat{b}$ & $a$ & $b$
\end{tabular}

For the pessimists, the frequency of intentions to buy and purchases are, assuming independence within each response group:

$\begin{array}{lcc} & \text { Intentions } & \text { Purchases } \\ \text { Both A and B } & (0.5 \hat{a})(0.5 \hat{b})(N / 3) & a b N / 3 \\ \text { Neither A nor B } & (1.0-0.5 \hat{a})(1.0-0.5 \hat{b})(N / 3) & (1-a)(1-b)(N / 3) \\ \text { A, not B } & (0.5 \hat{a})(1.0-0.5 \hat{b})(N / 3) & a(1-b)(N / 3) \\ \text { B, not A } & (0.5 \hat{b})(1.0-0.5 \hat{a})(N / 3) & b(1-a)(N / 3)\end{array}$

Multiplying, adding the comparable frequencies for the other two groups, and combining terms, aggregate intentions to buy both $\mathrm{A}$ and $\mathrm{B}$ are

$$
0.25 a \hat{b} \frac{N}{3}+a \hat{b} \frac{N}{3}+4 \hat{a} \hat{b} \frac{N}{3} \text {, or } 1.75 a \hat{b} N,
$$

the figure shown in the table.

The number 1.75 is simply the (weighted) mean value of the squares of rates assumed for buying intentions in the three response groups-normal, pessimistic, and optimistic households. That is,

$$
1.75=\left(1.0^{2} \frac{N}{3}+0.5^{2} \frac{N}{3}+2.0^{2} \frac{N}{3}\right) \div 3 N
$$


The number $1.17^{2}$ is simply the square of the (weighted) mean intentions rates assumed for the three groups, that is,

$$
1.17^{2}=\left[\left(1.0 \frac{\mathrm{N}}{3}+0.5 \frac{\mathrm{N}}{3}+2.0 \frac{\mathrm{N}}{3}\right) \div 3 \mathrm{~N}\right]^{2}
$$

Thus, response bias will result in the observed intentions pattern showing a greater degree of interdependence than the observed purchase pattern whenever the rates of buying intentions in the response groups are such that the mean of the squared rates exceeds the square of the mean rate; more simply, whenever the intentions rates for the response groups vary from one another. This criterion seems to apply regardless of the relative sizes of the response groups in the sample. The illustration assumed equality of sample size, but the assumption is unnecessary. Further, this result follows regardless of the magnitudes of the differences in intentions rates for the response groups. In effect, a comparison of the interdependence patterns for buying intentions and purchases seems to be a definitive test of response bias, other things being the same.

EMPIRIGAL FINDINGS ON RESPONSE BIAS

Several pairs of commodities were selected for the empirical analysis. These are, with the indicated designations,

$$
\begin{aligned}
& A_{1,2}=\text { automobile, furniture } \\
& A_{1,3}=\text { automobile, room air conditioner } \\
& A_{1,4}=\text { automobile, high-fidelity equipment } \\
& A_{3,5}=\text { room air conditioner, clothes dryer } \\
& A_{6,7}=\text { range, refrigerator } \\
& A_{8,9}=\text { garbage disposal unit, dishwasher } \\
& A_{4,10}=\text { high-fidelity equipment, television set }
\end{aligned}
$$

The first four pairs have no apparent complementarity in either use or purchase; hence, it was anticipated that households purchasing one of these commodities would be about as likely as others to purchase the second commodity. On the other hand, it was anticipated that joint purchases of the two commodities in the fifth and sixth pairs would be more common than predicted on the assumption of independence, since purchase of both items in each pair frequently accompanies acquisition of a house or renovation of a kitchen. And in the last pair it was anticipated that joint purchases might be less common than predicted on the assumption of independence.

It seemed desirable to test data for more than one intentions question; 
consequently, I selected one question with a relatively high probability cut-off point-definite intentions to buy within twelve months-and another with a much lower probability cut-off-probable or possible intentions to buy within twelve months. Chi-square is the appropriate test of independence. The observed frequencies in each of the four cells - purchased both A and B, purchased neither, ... . etc.-are tabulated directly; the predicted frequencies, assuming independence, are $a b N$, etc., as discussed above. The four groups were combined into two because both the predicted (and observed) frequencies in the $a b N$ or $\hat{a} \hat{b} N$ cells are generally very small (occasionally, less than one case), and the chi-square test loses validity with cells of this size. Hence the intended-to-buy (purchased) both and intended-to-buy (purchased) neither cells have been combined, as have the remaining two cells. No information is lost by this procedure, because any difference between observed and predicted frequencies necessarily has the same magnitude and sign in each of the combined cells. ${ }^{2}$

Chi-square statistics were computed for the sample as a whole, and for a subsample of relatively high- and relatively low-income households. Table B-2 summarizes the results for the seven pairs of commodities designated above as $A_{1,2}, \ldots, A_{4,10}$ for purchases and both definite and probable-possible buying intentions, and for both high- and low-income subgroups as well as for the total sample.

To determine whether there are systematic differences among households in the interpretation of buying intentions questions, the independence patterns for buying intentions and purchases must be compared.

${ }^{2}$ Chi-square for a $2 \times 2$ classification contains only one degree of freedom. Given the frequency of purchases or intentions to buy $A$ and $B$ and the sample size, tabulation of the observed frequency in any one of the four cells fixes the other three, as does computation of any one of the predicted frequencies. Suppose observed and predicted $2 \times 2$ tables are as follows, where 10 people report intentions to buy $\mathrm{A}, 20$ report intentions to buy B, 5 report intentions to buy both, and the sample contains 100 people:

\begin{tabular}{|c|c|c|c|c|c|c|}
\hline \multirow{3}{*}{$\begin{array}{l}\text { INTENTIONS } \\
\text { TO BUY B }\end{array}$} & \multicolumn{6}{|c|}{ INTENTIONS TO BUY A } \\
\hline & \multicolumn{3}{|c|}{ Observed Frequencies } & \multicolumn{3}{|c|}{ Predicted Frequencies } \\
\hline & Yes & No & Total & Yes & No & Total \\
\hline Yes & 5 & 15 & (20) & 2 & 18 & (20) \\
\hline No & 5 & 75 & 80 & 8 & 72 & 80 \\
\hline Total & (10) & 90 & $(100)$ & (10) & 90 & $(100)$ \\
\hline
\end{tabular}

The frequencies in parentheses are necessarily common to both parts of the table. The rest of the observed frequencies can be filled in once it is known that five people intended to buy both commodities; similarly, once $\hat{a} \hat{b} N=2-0.20 \times 0.10 \times 100-$ is computed, the rest of the predicted frequencies are determined. And the difference between predicted and actual in both sets of diagonal cells must be exactly the same in both magnitude and sign. 


\begin{tabular}{|c|c|c|c|c|c|c|c|}
\hline & \multicolumn{7}{|c|}{ Commodity Pairs } \\
\hline & $A_{1,2}$ & $A_{1,3}$ & $A_{1.4}$ & $A_{3,5}$ & $A_{6.7}$ & $A_{8.9}$ & $A_{4,1}$ \\
\hline \multicolumn{8}{|c|}{ ALL HOUSEHOLdS $(N=3157)$} \\
\hline $\begin{array}{l}\text { Purchases } \\
\text { Definite intentions to buy } \\
\text { Probable-possible intentions to buy }\end{array}$ & $\begin{array}{l}0.0 \\
3.0 \\
3.0\end{array}$ & $\begin{array}{l}0.0 \\
0.4 \\
3.4\end{array}$ & $\begin{array}{l}0.0^{\mathrm{a}} \\
0.8 \\
0.0\end{array}$ & $\begin{array}{l}0.1 \\
0.7 \\
0.2\end{array}$ & $\begin{array}{l}47.5^{b} \\
34.2^{b} \\
42.0^{b}\end{array}$ & $\begin{array}{l}28.2^{b} \\
15.3^{b} \\
18.4^{b}\end{array}$ & $\begin{array}{l}0.8 \\
1.2 \\
1.9\end{array}$ \\
\hline \multicolumn{8}{|c|}{ HOUSEHOLDS WITH FAMILY INCOME UNDER $\$ 7,500(N=1144)$} \\
\hline $\begin{array}{l}\text { Purchases } \\
\text { Definite intentions to buy } \\
\text { Probable-possible intentions to buy }\end{array}$ & $\begin{array}{l}0.1 \\
2.3 \\
2.6\end{array}$ & $\begin{array}{l}0.4^{\mathrm{a}} \\
0.4 \\
1.1\end{array}$ & $\begin{array}{l}0.0 \\
1.4 \\
0.6\end{array}$ & $\begin{array}{l}0.0 \\
0.4 \\
0.2\end{array}$ & $\begin{array}{l}14.1^{\mathrm{b}} \\
19.0^{\mathrm{b}} \\
25.1^{\mathrm{b}}\end{array}$ & $\begin{array}{l}2.7 \\
1.5 \\
2.5\end{array}$ & $\begin{array}{l}0.0 \\
0.8 \\
0.3\end{array}$ \\
\hline \multicolumn{8}{|c|}{ HOUSEHOLDS WITH FAMILY INCOME OF $\$ 10,000$ OR MORE $(N=1103)$} \\
\hline $\begin{array}{l}\text { Purchases } \\
\text { Definite intentions to buy } \\
\text { Probable-possible intentions to buy }\end{array}$ & $\begin{array}{l}0.0^{\mathrm{a}} \\
1.2 \\
1.9\end{array}$ & $\begin{array}{l}0.3 \\
0.0 \\
2.0\end{array}$ & $\begin{array}{l}0.6^{\mathrm{a}} \\
0.2 \\
0.0\end{array}$ & $\begin{array}{l}0.6 \\
0.1 \\
0.0\end{array}$ & $\begin{array}{r}19.0^{\mathrm{b}} \\
15.1^{\mathrm{b}} \\
8.9^{\mathrm{b}}\end{array}$ & $\begin{array}{r}13.8^{\mathrm{b}} \\
12.3^{\mathrm{b}} \\
9.9^{\mathrm{b}}\end{array}$ & $\begin{array}{l}0.9 \\
0.3 \\
0.1\end{array}$ \\
\hline
\end{tabular}

Source: Basic data from Consumer Purchase Study, NBER.

Note: See accompanying text for durables designated by the subscripts. Chi-square is computed as the difference between the observed and predicted number of households reporting intentions to buy (purchases) for both or neither of the commodity pairs, and for one but not the other or the reverse. For example, commodity pair $A_{1.2}$ (automobile vis-à-vis furniture) showed the following observed and predicted combinations for purchases, using the sample as a whole.

\begin{tabular}{|c|c|c|c|c|c|c|c|}
\hline \multirow{2}{*}{$\begin{array}{r}A_{2} \\
\text { Yes }\end{array}$} & \multicolumn{3}{|c|}{$\begin{array}{l}\text { OBSERVED PURCHASES } \\
\qquad A_{1}\end{array}$} & \multirow[b]{2}{*}{$A_{2}$} & \multicolumn{3}{|c|}{$\begin{array}{l}\text { PREDICTED PURCHASES } \\
\qquad A_{1}\end{array}$} \\
\hline & $\begin{array}{l}\text { Yes } \\
133\end{array}$ & No & Total & & Yes & No & Total \\
\hline No & 509 & 2,000 & $\begin{array}{r}040 \\
2,509\end{array}$ & No & $\begin{array}{l}131.8 \\
510.2\end{array}$ & $\begin{array}{r}510.2 \\
1.998 .8\end{array}$ & $\begin{array}{r}040 \\
2,509\end{array}$ \\
\hline Total & 642 & 2,515 & 3,157 & Total & 642 & 2,515 & 3,157 \\
\hline
\end{tabular}

Thus, the sums of purchases of both commodities or of neither are:

$\begin{array}{ll}\text { Observed } & 2,133 \\ \text { Predicted } & 2,130.6\end{array}$

The sums of the other cells are:

Chi-square is computed as

$\begin{array}{ll}\text { Observed } & 1,024 \\ \text { Predicted } & 1,026.4\end{array}$

$$
\frac{(2.4)^{2}}{2,130.6}+\frac{(2.4)^{2}}{1,026.4}, \text { or } 0.0
$$

a The predicted frequency of intentions (purchases) for both commodities in the pair is greater than the observed frequency, indicating a pattern of negative interdependence. In all other cases, predicted frequency of intentions (purchases) for both commodities is less than the observed frequency.

b These show a significant degree of interdependence at the 0.01 level. The critical values of $\chi^{2}$ with one degree of freedom are: 
The observed pattern for purchases is affected by events that occur after the formulation of buying intentions, hence would not be observed in the intentions data because the event had not been foreseen. Many events of this kind occur between the date when buying intentions are reported and the end of the forecast period. For example, some households report intentions to buy a large number of durable goods because they expect to move to a new residence. Some of these households will move during the forecast period, purchasing a number of durables in the process; both their buying intentions and purchases will show a high degree of interdependence. Others of this group of intenders will not move during the period, and their buying intentions would presumably show more interdependence than their purchases because of this. But some households will move that had not anticipated a change in residence, and their purchases would presumably show a higher degree of interdependence than their buying intentions. On the whole, it seems reasonable to assume that the influence of such events, and of unanticipated events generally, will be random with respect to the observed pattern of independence among purchases, or if nonrandom, that there will be a corresponding influence on buying intentions.

The data do not support the proposition that response bias exists; more accurately, they do not support the proposition that a serious response bias characterizes the sample. In the two cases where the intentions data show statistically significant interdependence, purchases also show a statistically significant degree of interdependence. And in each of these cases both intentions questions-definite and probable-possible-show significant positive interdependence. In the other five cases, purchases show no significant deviation from a pattern of independence; and in all five cases, neither intentions question shows a significant deviation from independence.

The hypothesized negative interdependence between purchases of highfidelity equipment and television sets is not apparent in the data. The only one of the seven commodity pairs in which observed joint purchases are fewer than predicted by the no-association hypothesis (automobiles and high-fidelity equipment) shows a chi-square value of less than 0.1 . Although all possible combinations of commodity pairs were not tested, it seems probable that none would show a pattern of significant negative interdependence. The implication is that expenditures for durables typically tend to be substitutes for savings or for expenditures on nondurables rather than for other items in the durables category.

The results for subgroups of relatively low- and high-income house- 
holds accord with those for the sample as a whole, although the evidence suggests that the patterns may be slightly different for households in the respective income classes. As before, all cases of statistically significant interdependence in purchases are matched by a corresponding pattern in the intentions data. But disregarding the question of statistical significance, both buying intentions questions compared to purchases tend to show a greater degree of positive interdependence for households in the relatively low-income group, while the reverse is true for households in the relatively high-income classes. In the middle panel of Table B-2, for example, six of the seven commodity pairs show higher chi-square values for both intentions variants than for purchases; among relatively highincome households, in contrast, five of seven commodity pairs show higher values of chi-square for purchases than for definite buying intentions; four of seven, higher chi-square values for purchases than for probable-possible intentions (bottom panel). None of these differences is statistically significant.

Additional evidence is provided by the analysis of data for more homogeneous subgroups. The sample was cross-classified into five income and three life-cycle groups, with sample sizes as shown in the tabulation below:

\begin{tabular}{lccr} 
& \multicolumn{2}{c}{ Life-Cycle Class: } & Husband-Wife Households, Head \\
Income Class & $25-35$ & $35-44$ & $45-64$ \\
\hline Under $\$ 5,000$ & 131 & 55 & 56 \\
$\$ 5,000-\$ 7,499$ & 460 & 266 & 176 \\
$\$ 7,500-\$ 9,999$ & 383 & 338 & 189 \\
$\$ 10,000-\$ 14,999$ & 206 & 342 & 209 \\
$\$ 15,000$ and over & 66 & 133 & 147
\end{tabular}

Frequencies of purchases and of both definite and probable-possible intentions were computed for each commodity within each of the fifteen subgroups; predicted frequencies were calculated for the seven commodity pairs within each of the subgroups, and the corresponding actual frequencies tabulated. Both predicted and observed frequencies were converted to proportions, and $t$ ratios were computed for the difference between predicted and observed proportions in the purchased (intendedto-buy) both-A-and-B cell. ${ }^{3}$ All told, there were $105 t$ ratios for purchases, and the same number for both of the intentions questions-one

${ }^{8}$ Let $p_{A}$ be the proportion of any given subgroup reporting purchases of commodity $\mathrm{A} ; p_{B}$, the proportion reporting purchases of commodity $\mathrm{B}$. Then $p_{A} p_{B}$ is the proportion expected to purchase both $A$ and $B$, assuming that purchases of $A$ are independent of whether or not $\mathrm{B}$ was purchased, and vice versa. Designating $p_{A} p_{B}$, the predicted proportion of joint purchases, as $f_{p}$, and designating the observed proportion as $f_{o}$, the $t$ ratio is $\frac{f_{o}-f_{p}}{\sigma\left(f_{o}-f_{p}\right)}$. 
$t$ ratio for each of the seven commodity pairs within each of the fifteen subgroups.

Table B-3 summarizes the joint distribution of these $t$ ratios by purchases versus definite intentions to buy and purchases versus probable-possible intentions to buy. The $t$ ratios are classified according to whether the observed frequency $\left(f_{0}\right)$ is greater or less than the predicted frequency $\left(f_{p}\right)$ and whether the $t$ ratio is less than 1 , between 1 and 2 , or greater than 2 . The data are arranged so that observations below the diagonal from upper left to lower right are cases where buying intentions show a stronger degree of interdependence (or a weaker degree of negative interdependence) than

TABLE B-3

Test of Response Bias by Joint Distribution of $t$ Ratios

\begin{tabular}{|c|c|c|c|c|c|c|c|}
\hline & \multicolumn{7}{|c|}{$t$ Ratios for Purchases } \\
\hline & \multicolumn{3}{|c|}{$f_{0}<f_{p}$} & \multicolumn{3}{|c|}{$f_{0}>f_{p}$} & \multirow[b]{2}{*}{ Total } \\
\hline & $t \geqq 2$ & $2<t \geqq 1$ & $t<1$ & $t<1$ & $1 \leqq t>2$ & $t \geqq 2$ & \\
\hline \multicolumn{8}{|l|}{$\begin{array}{l}t \text { ratios for definite buying } \\
\text { intentions } \\
f_{0}<f_{p}\end{array}$} \\
\hline$t \geqq 2$ & 0 & $\mathbf{0}$ & 0 & $\mathbf{0}$ & 0 & 0 & 0 \\
\hline $2<t \geqq 1$ & 0 & 0 & 1 & 0 & 0 & 0 & 1 \\
\hline $\begin{array}{c}t<1 \\
f_{0}>f_{p}\end{array}$ & 0 & 1 & 18 & 10 & 4 & 1 & 34 \\
\hline$t<1$ & 0 & 2 & 16 & 20 & 8 & 0 . & 46 \\
\hline $1 \leqq t>2$ & 0 & 0 & 3 & 5 & 10 & 3 & 21 \\
\hline$t \geqq 2$ & 0 & $\mathbf{0}$ & 1 & 0 & 1 & 1 & 3 \\
\hline Total & 0 & 3 & 39 & 35 & 23 & 5 & 105 \\
\hline \multicolumn{8}{|l|}{$\begin{array}{l}t \text { ratios for probable-possible } \\
\text { buying intentions } \\
f_{0}<f_{p}\end{array}$} \\
\hline$t \geqq 2$ & 0 & 0 & 0 & 0 & 0 & 0 & 0 \\
\hline $2<t \geqq 1$ & 0 & 0 & 2 & 0 & 1 & 0 & 3 \\
\hline$t<1$ & $\mathbf{0}$ & 2 & 16 & 8 & 2 & $\mathbf{0}$ & 28 \\
\hline \multicolumn{8}{|l|}{$f_{0}>f_{p}$} \\
\hline$t<1$ & 0 & 1 & 17 & 22 & 8 & 0 & 48 \\
\hline $1 \leqq t>2$ & 0 & 0 & 4 & 4 & 10 & 3 & 21 \\
\hline$t \geqq 2$ & $\mathbf{0}$ & 0 & $\mathbf{0}$ & 1 & 2 & 2 & 5 \\
\hline \multirow[t]{4}{*}{ Total } & $\mathbf{0}$ & 3 & 39 & 35 & 23 & 5 & 105 \\
\hline & & SUMMARY & & & & & \\
\hline & Upper & Lower & & & & & \\
\hline & Panel & Panel & Total & & & & \\
\hline Observations along diagonal & 49 & 50 & 99 & & & & \\
\hline Observations above diagonal & 27 & 24 & 51 & & & & \\
\hline Observations below diagonal & 29 & 31 & 60 & & & & \\
\hline Total & 105 & 105 & 210 & & & & \\
\hline
\end{tabular}

Source: Basic data from Consumer Purchase Study, NBER.

Nore: See accompanying text for explanation. 
purchases; observations above the diagonal, cases where purchases are more highly interdependent; and observations along the diagonal, cases where the degree of interdependence is approximately the same for both purchases and intentions.

These data provide evidence on several points. First, differences among households in the interpretation of buying-intentions questions do not appear to be a serious problem in this sample. Almost half the total observations fall along the diagonal; their $t$ ratios for purchases and buying intentions are therefore approximately equal in magnitude, and $\left(f_{o}-f_{p}\right)$ has the same algebraic sign for both purchases and intentions. Further, only 20 of 210 observations fall more than one category away from the diagonal. Second, response bias among households does exist, and there is some indication that it is more serious for intentions variants with a relatively low probability cut-off. I infer this from the fact that more observations appear below the diagonal than above, and relatively more are below than above in the lower panel than in the upper one. Further, of the observations that are more than two categories removed from the diagonal, six of nine in the lower panel are below the diagonal while only six of eleven are below the diagonal in the upper one. Finally, it appears that the interdependence patterns for purchases are negative about as often as they are positive if commodity pairs with strong complementarity in use are excluded, such as the range-refrigerator or garbage disposal unit-dishwasher combinations. These two combinations comprise all the highly interdependent purchase patterns in Table B-3, although the $t$ ratios are generally below 2 because of the small sample size. Excluding these cases, the remainder seem to be about evenly distributed around the dividing line where $f_{o}=f_{p}$. It may be that other combinations of commodities have a strong pattern of negative interdependence, but none of the ones used above seems to have this characteristic.

It should be noted that these conclusions may not apply to samples selected at random from the population. All of the analysis in this monograph is based on data for a thoroughly unrepresentative sample of households. In most cases, it is possible to check whether the results are sensitive to variations in such household characteristics as income, lifecycle status, or education - for which the Consumers Union sample is known to be atypical. If the results are not sensitive to such factors, it can be argued that they are likely to be applicable to the population generally. But in this chapter I have shown that differences in the degree of interdependence for purchases and buying intentions, though small, are apparently rather persistent for the lowest income groups in the sample, 
while no differences at all are apparent for the highest income groups. Hence, a random population sample might well be characterized by a much stronger degree of interdependence for buying intentions than for purchases.

\section{An Analysis of Substitution Among Intenders}

The third of the questions raised at the beginning of this appendix requires a rather different arrangement of the empirical data. The question here is whether a household reporting an intention to buy commodity A but not purchasing is more apt to purchase commodity B than a household neither reporting an intention to buy nor purchasing $A$. If this is the case it clearly makes more sense to combine the individual commodity buying intentions for each household into an aggregate, rather than to deal with them separately. If it is not, aggregation serves no particular point and may tend to muddy relationships that actually exist.

This problem is cumbersome for empirical analysis. It does no good to compare total purchases for a group of households that reported intentions to buy commodity A, but did not purchase, with total purchases for households that neither reported intentions to buy nor bought commodity A; it is also necessary to know the extent to which these respective groups of households had reported buying intentions for other commodities. Moreover, the analysis in Chapters 3 and 4 suggests that both affirmative and negative responses to buying-intentions questions reflect a continuous distribution of ex ante purchase probabilities rather than a dichotomous distribution of probabilities equal to unity and zero. The most efficient procedure seems to me to be a comparison of the relation between aggregate purchases and aggregate buying intentions for groups of households that, ex post, differ with respect to their reported intentions to buy or purchases of some particular commodity. For simplification I first make the extreme assumption (which I will later drop) that households reporting intentions to buy have purchase probabilities equal to unity; those not reporting intentions, probabilities of zero.

The analysis concerns aggregate intentions and purchases for households classified with respect to intentions and purchases relating to a specific commodity-any of the items for which data are available. Let $P$ represent (weighted) aggregate purchases for all $\mathrm{A}, \mathrm{B}, \ldots, \mathrm{N}$ commodities, including the one used as the basis for classifying into groups; let $\hat{P}$ represent (weighted) aggregate intentions to buy, defined in the same way. Let $P^{\prime}$ represent aggregate purchases of all commodities exclusive of the one used as the basis for classification; let $\hat{P}^{\prime}$ represent aggregate buying 
intentions, similarly defined. Then $P / \hat{P}$ or $P^{\prime} / \hat{P}^{\prime}$ are ratios of aggregate purchases to aggregate intentions. To denote the household's intentions and purchases of a given commodity $\mathrm{A}, \mathrm{B}, \mathrm{C}, \ldots$, or $\mathrm{N}$, two subscripts are used; the first indicates whether or not the household intended to buy: $1=$ yes, $0=$ no; the second, whether or not they purchased: $1=$ yes, $0=$ no. Thus $(P / \hat{P})_{11}$ is the ratio of aggregate purchases to aggregate buying intentions, including those for the given commodity $\mathrm{A}, \mathrm{B}, \mathrm{C}, \ldots$, or $\mathrm{N}$, for households that intended to buy and purchased $\mathrm{A}, \mathrm{B}, \ldots$, or $\mathrm{N}$ during the forecast period. Similarly, $\left(P^{\prime} / \hat{P}^{\prime}\right)_{01}$ is the ratio of aggregate purchases to aggregate buying intentions, excluding those involving commodity $\mathrm{A}, \mathrm{B}, \mathrm{C}, \ldots$, or $\mathrm{N}$, for households that had not reported intentions to buy $\mathrm{A}, \mathrm{B}, \mathrm{C}, \ldots$, or $\mathrm{N}$ but had purchased during the forecast period. A leading subscript designates the commodity used as the basis for classification into intended to buy and bought, etc. Thus ${ }_{A}(P / \hat{P})_{00}$ represents the ratio of aggregate purchases to aggregate buying intentions for households that had neither intended to buy nor purchased A during the forecast period.

The notation is further simplified by adopting the convention that $P / \hat{P}$ is $Q$, and that $P^{\prime} / \hat{P}^{\prime}$ is $Q^{\prime}$. Hence, ${ }_{A} Q_{01}$ represents the ratio of aggregate purchases to aggregate buying intentions, including those for commodity A, for households that purchased $\mathrm{A}$ but had not reported intentions to do so. ${ }_{B} Q^{\prime}{ }_{10}$ represents the ratio of aggregate purchases to aggregate intentions, excluding those for commodity B, for households that reported buying intentions but had not purchased B during the forecast period.

The possible relationships can now be defined. There might be complete substitution: any household that reported intentions to buy A would either buy it or some equivalent item; any household that bought $\mathrm{A}$ without reporting an intention to buy would have reported intentions to buy an equivalent item that would not have been purchased. In short, the sum of intentions and purchases for all commodities would be the same regardless of whether the households had intended to buy and bought $\mathrm{A}$, intended to buy and not bought $\mathrm{A}$, etc. In the notation above,

$$
{ }_{A} Q_{11}={ }_{A} Q_{10}={ }_{A} Q_{01}={ }_{A} Q_{00} ;
$$

and these ratios would all be equal to unity. The ratio of purchases to intentions excluding A would follow the reverse pattern from that of the classification with respect to A; that is, those who had intended to buy but had not purchased A would have made relatively more purchases of 
$\mathrm{B}, \mathrm{C}, \ldots, \mathrm{N}$, etc. In the above notation

$$
{ }_{A} Q^{\prime}{ }_{10}>{ }_{A} Q^{\prime}{ }_{11}={ }_{A} Q^{\prime} 00>{ }_{A} Q^{\prime} 01
$$

A second possibility involves less than complete substitution. Households intending to buy but not purchasing $A$ would have purchased more $\mathrm{B}, \mathrm{C}, \ldots, \mathrm{N}$, relative to intentions, than households intending to buy and buying $A$, but not enough more to compensate for the difference in purchases of A. Similarly, households that had not intended to buy $A$ but had purchased would have bought less $\mathrm{B}, \mathrm{C}, \ldots, \mathrm{N}$, relative to intentions, than households that had neither intended to buy nor purchased; but, again, not enough less to compensate for the difference in purchases of $\mathrm{A}$. Those whose actions corresponded with their intentions would presumably have about the same ratio of $P$ to $\hat{P}$.

In the notation used above,

and

$$
{ }_{A} Q_{01}>{ }_{A} Q_{00} \gtreqless{ }_{A} Q_{11}>{ }_{A} Q_{10},
$$

Also,

$$
{ }_{A} Q_{01}>{ }_{A} Q_{10} .
$$

and

$$
{ }_{A} Q^{\prime}{ }_{10}>{ }_{A} Q^{\prime}{ }_{11} \gtreqless{ }_{A} Q^{\prime}{ }_{00}>{ }_{A} Q^{\prime}{ }_{01},
$$

$$
{ }_{A} Q^{\prime}{ }_{10}>{ }_{A} Q^{\prime}{ }_{01} \text {. }
$$

In short, the pattern of the $Q$ and $Q^{\prime}$ ratios would be exactly the reverse of each other. Those reporting intentions to buy A but not purchasing would show relatively more purchases of $\mathrm{B}, \mathrm{C}, \ldots, \mathrm{N}$ but relatively fewer of $\mathrm{A}, \mathrm{B}, \mathrm{C}, \ldots, \mathrm{N}$ than those reporting intentions and purchasing $\mathrm{A}$. On the other hand, households that had purchased $A$ but had not reported intentions to buy would show relatively fewer purchases of $B, C, \ldots, N$ but relatively more of $\mathrm{A}, \mathrm{B}, \mathrm{C}, \ldots, \mathrm{N}$ than those reporting neither intentions nor purchases.

The third possibility is zero substitution. In this case, intentions or purchases vis-à-vis $\mathrm{A}$ would have no effect on the relation between purchases and intentions vis-à-vis commodities $\mathrm{B}, \mathrm{C}, \ldots, \mathrm{N}$. The $Q^{\prime}$ ratios would be the same regardless of the A classification into which the household fell, while the $Q$ ratios would depend on the A classification. In sum, it would be found that:

and

$$
{ }_{A} Q_{01}>{ }_{A} Q_{00} \gtreqless{ }_{A} Q_{11}>{ }_{A} Q_{10} ;{ }_{A} Q_{01}>{ }_{A} Q_{10},
$$

$$
{ }_{A} Q^{\prime}{ }_{11}={ }_{A} Q^{\prime}{ }_{10}={ }_{A} Q^{\prime}{ }_{01}={ }_{A} Q^{\prime}{ }_{00}
$$


The remaining possibility may be thought of as negative substitution or complementarity. In this case, households intending to buy $\mathrm{A}$ but not purchasing would make relatively fewer purchases of $\mathrm{B}, \mathrm{C}, \ldots, \mathrm{N}$ than households that intended to buy and did so. Those that purchased $\mathrm{A}$ but had not reported intentions to do so would make relatively more purchases of $\mathrm{B}, \mathrm{C}, \ldots, \mathrm{N}$ than those that had neither bought nor intended to buy. By the same token, those that intended to buy but did not purchase $\mathrm{A}$ would make relatively fewer purchases of $\mathrm{B}, \mathrm{C}, \ldots, \mathrm{N}$ than those that had purchased $A$ but had not reported intentions to buy. As before, the $Q^{\prime}$ ratios for those whose intentions coincided with their actions must be between the $Q^{\prime}$ ratios for the other groups. The $Q$ ratios necessarily follow the same pattern except that the differences are bound to be greater. In the 01 group, for example, $Q$ must be larger than $Q^{\prime}$ because the numerator must increase and the denominator does not change; in the 10 group $Q$ must be smaller than $Q^{\prime}$, since the numerator does not change and the denominator necessarily increases.

In sum:

$$
\begin{gathered}
{ }_{A} Q_{01}>{ }_{A} Q_{00} \gtreqless{ }_{A} Q_{11}>{ }_{A} Q_{10} ;{ }_{A} Q_{01}>{ }_{A} Q_{10}, \\
{ }_{A} Q^{\prime}{ }_{01}>{ }_{A} Q^{\prime}{ }_{00}{ }_{A} Q^{\prime}{ }_{11}>{ }_{A} Q^{\prime}{ }_{10} ;{ }_{A} Q^{\prime}{ }_{01}>{ }_{A} Q^{\prime}{ }_{10}, \\
{ }_{A} Q_{01}>{ }_{A} Q^{\prime}{ }_{01},{ }_{A} Q_{10}<{ }_{A} Q^{\prime}{ }_{10}
\end{gathered}
$$

It should be noted that these tests may not show identical or even similar patterns for all the $\mathrm{A}, \mathrm{B}, \mathrm{C}, \ldots, \mathrm{N}$ commodities. For example, it is perfectly conceivable that purchases of other items are completely unaffected by the purchase of a refrigerator, but are affected by the purchase of an automobile. On a priori grounds, a combination of positive substitution when $\mathrm{A}$ is the basis for classification and negative substitution when B is the classification basis appears less likely; yet there seems no necessary reason why this could not be the case.

The relation between $Q$ and $Q^{\prime}$ ratios for the four possible cases outlined above, for the $N$ th commodity, is summarized as follows:

1. Complete substitution

and

$$
{ }_{N} Q_{11}={ }_{N} Q_{10}={ }_{N} Q_{01}={ }_{N} Q_{00},
$$

$$
{ }_{N} Q^{\prime}{ }_{10}>{ }_{N} Q^{\prime}{ }_{11}={ }_{N} Q^{\prime}{ }_{00}>{ }_{N} Q^{\prime}{ }_{01} .
$$

2. Some substitution, but less than complete,

$$
\begin{array}{r}
{ }_{N} Q_{01}>{ }_{N} Q_{00} \gtreqless{ }_{N} Q_{11}>{ }_{N} Q_{10} ;{ }_{N} Q_{01}>{ }_{N} Q_{10}, \\
{ }_{N} Q^{\prime}{ }_{10}>{ }_{N} Q^{\prime}{ }_{11} \gtreqless{ }_{N} Q^{\prime}{ }_{00}>{ }_{N} Q^{\prime}{ }_{01} ;{ }_{N} Q^{\prime}{ }_{10}>{ }_{N} Q^{\prime}{ }_{01}
\end{array}
$$


3. Neither substitution nor complementarity

$$
\begin{gathered}
{ }_{N} Q_{01}>{ }_{N} Q_{00} \gtreqless{ }_{N} Q_{11}>{ }_{N} Q_{10} ;{ }_{N} Q_{01}>{ }_{N} Q_{10}, \\
{ }_{N} Q^{\prime}{ }_{11}={ }_{N} Q^{\prime}{ }_{10}={ }_{N} Q^{\prime}{ }_{01}={ }_{N} Q^{\prime}{ }_{00} .
\end{gathered}
$$

4. Negative substitution or complementarity

$$
\begin{gathered}
{ }_{N} Q_{01}>{ }_{N} Q_{00} \gtreqless{ }_{N} Q_{11}>{ }_{N} Q_{10} ;{ }_{N} Q_{01}>{ }_{N} Q_{10}, \\
{ }_{N} Q^{\prime}{ }_{01}>{ }_{N} Q^{\prime}{ }_{00} \gtreqless{ }_{N} Q^{\prime}{ }_{11}>{ }_{N} Q^{\prime}{ }_{10} ;{ }_{N} Q^{\prime}{ }_{01}>{ }_{N} Q^{\prime}{ }_{10}, \\
{ }_{N} Q_{01}>{ }_{N} Q^{\prime}{ }_{01},{ }_{N} Q_{10}<{ }_{N} Q^{\prime}{ }_{01}
\end{gathered}
$$

From this set of relationships it is clear that the $Q$ ratios are a definitive test for complete substitution. If these ratios are all equal, there must be complete substitution; otherwise this cannot be the case. The $Q$ ratios follow identical patterns if there is some, none, or negative substitution; hence, they cannot discriminate in these cases. But the pattern of the $Q^{\prime}$ ratios, if there is positive but less than complete substitution, is opposite to that for negative substitution or complementarity; and all the $Q^{\prime}$.ratios are equal if there is zero substitution.

At this point the assumption is dropped that households reporting intentions have perfect certainty about purchasing and, hence, ex ante purchase probabilities equal to one, as is the companion assumption that nonintenders have perfect certainty about not purchasing, i.e. ex ante purchase probabilities of zero. The analysis in the text makes it quite clear that these assumptions are unrealistic. If so, what is the affect on the $Q$ and $Q^{\prime}$ ratios?

In the first place, the average $Q$ ratio for the sample as a whole need no longer be equal to unity. Instead, the level of the $Q$ ratio is determined by the characteristics of the buying intentions question. It will be recalled that $Q$ is defined as the ratio of (weighted) aggregate purchases to aggregate intentions, that is, as $P / \hat{P}$. But $P$ can be written as the product of the mean probability of purchase and the number of households in the sample, i.e., $\sum_{a}^{n} x^{\prime} N$. Although $x^{\prime}$ cannot be observed, the fraction of the sample purchasing- $x$-is an unbiased estimate of $x^{\prime}$. I have already shown that $x$ is equal to $s+p(r-s)$, where $s$ is the purchase rate for nonintenders; $r$, the purchase rate for intenders; and $p$, the proportion of intenders in the sample. It follows that:

$$
P=\sum_{a}^{n} x N=\sum_{a}^{n}[s+p(r-s)] N
$$


The denominator of the $Q$ ratio $(\hat{P})$ is simply $\sum_{a}^{n} p N$, where $p$ is the proportion of the sample reporting intentions to buy each of the $A, B$, . . . , $\mathrm{N}$ commodities and $N$ is the sample size. Consequently,

$$
Q=\frac{P}{\hat{P}}=\frac{\sum_{a}^{n}[s+p(r-s)]}{\sum_{a}^{n} p}
$$

From this formula it is obvious that the $Q$ ratio will equal unity only by chance. In general, the level of the ratio depends on $p$, which in turn depends on the characteristics of the intentions question. When $p$ increases, previous discussion has shown that both $r-s$ and $s$ will fall provided that $x$ and $p$ are relatively small. Since all the $x$ and $p$ terms are considerably less than 0.5 , the $Q$ ratio must fall as $p$ increases, for the denominator must grow at a faster rate than the numerator.

However, the relative size of the $Q$ ratios in the several classes of households is not indicated. I will now investigate these ratios for the 11 and 10 groups - those intending to buy and purchasing, and those intending to buy but not purchasing. If a household falls in group 11 (intended, purchased) for the Ath commodity, it would appear that the household's probability of purchasing $\mathrm{B}, \mathrm{C}, \ldots$. or $\mathrm{N}$ should be less than if it had fallen in group 10 (intended, did not purchase). The expected value of total purchases for the $i$ th household is the sum of its ex ante purchase probabilities for $\mathrm{A}, \mathrm{B}, \mathrm{C}, \ldots, \mathrm{N}$. If the $i$ th household reported an intention to buy commodity A, it is known that one element in the sum of its purchase probabilities had a value somewhere between the cut-off point and unity. If the household purchased $A$, one of the elements in the sum of its purchases has a value of unity; while if the household did not purchase A, one of the elements in $P$ has a value of zero. On the average, it seems to follow that intenders who purchased (group 11) must have lower $Q^{\prime}$ ratios than intenders who did not purchase (group 10), that is, ${ }_{A} Q^{\prime}{ }_{11}$ must be less than ${ }_{A} Q^{\prime}{ }_{10}$. The relation between ${ }_{A} Q_{11}$ and ${ }_{A} Q_{10}$ might be anything. Ex ante, ${ }_{A} Q_{11}$ might have been equal to ${ }_{A} Q_{10}$; but no necessary relation exists between the (observed) ex post ${ }_{A} Q_{11}$ and ${ }_{A} Q_{10}$ ratios. The reason is simply that I have classified by a variable (purchase or nonpurchase of $\mathrm{A}$ ) that necessarily involves the propositions that

$$
\left(p_{A}\right)_{11}>\left(\hat{p}_{A}\right)_{11}
$$


and

$$
\left(p_{A}\right)_{10}<\left(\hat{p}_{A}\right)_{10}
$$

where $p_{A}$ represents observed purchases of commodity $A$; and $\hat{p}_{A}$, expected purchases.

However, further analysis indicates that this conclusion- ${ }_{A} Q^{\prime}{ }_{11}$ is necessarily less than ${ }_{A} Q^{\prime}{ }_{10}-$ may not hold unless the distribution of purchase probabilities among those reporting intentions to buy $\mathrm{A}, \mathrm{B}, \mathrm{C}, \ldots . . \mathrm{N}$ is randomly associated with the distribution of purchases. But I do not think it reasonable to assume that, among a group of intenders, households that purchased had the same ex ante mean probability as households that did not purchase. Rather, I would have thought that ex ante mean probability was likely to have been higher among intenders who purchased than among intenders who did not purchase. If so, ex ante purchase probability for commodities B, C, . . . , N might also be higher among $\mathrm{A}$ intenders who purchased than among those who did not purchase. This in itself would not be sufficient to change the above relation between ${ }_{A} Q^{\prime}{ }_{11}$ and ${ }_{A} Q^{\prime}{ }_{10}$, since any difference between these two groups in the mean probability of purchasing $\mathrm{B}, \mathrm{C}, \ldots$. . N may show up as a difference in the average level of intentions to buy these commodities. However, part of any such difference in mean probability is also likely to show up as a higher mean probability among both intenders and nonintenders, as well as in a different distribution of the two. In short, if the probability of purchasing $A$ is positively correlated with the probability of purchasing $\mathrm{B}, \mathrm{C}, \ldots ., \mathrm{N}$, holding constant intentions to buy $\mathrm{B}, \mathrm{C}, \ldots, \mathrm{N}$ as well as intentions to buy $\mathrm{A}$, the observed $Q^{\prime}$ ratio among $\mathrm{A}$ intenders might be larger for the 11 group than for the 10 group; and this may be the case even if, substituting ex ante purchase probabilities for reported intentions to buy, ${ }_{A} Q^{\prime}{ }_{11}$ is less than ${ }_{A} Q^{\prime}{ }_{10}$.

The same line of argument can be used to show that the relation between the $Q^{\prime}$ ratios for groups 01 and 00 is also impossible to predict from the probability model. If probabilities for A nonintenders were randomly associated with purchases of $\mathrm{A}$, or if purchase probabilities relating to $\mathrm{B}, \mathrm{C}, \ldots$. . N were uncorrelated with purchase probabilities for $\mathrm{A}$, holding intentions to buy constant, it would follow that

$$
{ }_{A} Q^{\prime}{ }_{01}<{ }_{A} Q^{\prime}{ }_{00}
$$

But if these assumptions do not hold, the observed relation might be ${ }_{A} Q^{\prime}{ }_{01}>{ }_{A} Q^{\prime}{ }_{00}$, although substituting ex ante probabilities, ${ }_{A} Q_{01}^{\prime}<{ }_{A} Q_{00}^{\prime}$.

The argument essentially proposes that classification of households into the above groups $(11,10,01,00)$ is likely to introduce a consistent bias into 
the relation between the observed $Q$ or $Q$ ' ratios and the "true" ratios-in which actual probabilities replace buying intentions. The observed ratios are defined as

$$
\begin{aligned}
{ }_{A} Q_{11,10,01,00} & ={ }_{A}(P / \hat{P})_{11,10,01,00} \\
{ }_{A} Q^{\prime}{ }_{11,10,01,00} & ={ }_{A}\left(P^{\prime} / \hat{P}^{\prime}\right)_{11,10,01,00}
\end{aligned}
$$

The $P$ term is the sum of actual purchases, and is presumably an estimate of the sum of ex ante purchase probabilities for households in the respective classes. The $\hat{P}$ term is the total number of buying intentions reported by households in the respective classes, but will not be an estimate of the sum of probabilities except by happenstance. If the summation of (unknown) ex ante purchase probabilities for households in the respective $11, \ldots, 00$ groups is not randomly associated with $\hat{P}$ in these same classes, the relation among ${ }_{A} Q_{11,10,01,00}$ or ${ }_{A} Q^{\prime}{ }_{11,10,01,00}$ cannot be predicted with any confidence. This is especially the case if the (unknown) purchase probabilities for $\mathrm{B}, \mathrm{C}, \ldots, \mathrm{N}$, holding constant intentions to buy $\mathrm{B}, \mathrm{C}, \ldots, \mathrm{N}$, happen to be positively correlated with the (unknown) probability of purchasing A, holding constant intentions to buy $\mathrm{A}$.

\section{EMPIRICAL FINDINGS ON SUBSTITUTION}

The net result is that the empirical findings based on the assumption of perfect certainty for both intenders and nonintenders become difficult if not impossible to interpret. The data (Table B-4) indicate that negative substitution or complementarity is the dominant pattern. In all but one case the $Q^{\prime}$ ratios show that

$$
\begin{aligned}
& { }_{A} Q^{\prime}{ }_{01}>{ }_{A} Q^{\prime}{ }_{00} \gtreqless{ }_{A} Q^{\prime}{ }_{11}>{ }_{A} Q^{\prime}{ }_{10} ;{ }_{A} Q^{\prime}{ }_{01}>{ }_{A} Q^{\prime}{ }_{10}, \\
& { }_{B} Q^{\prime}{ }_{01}>{ }_{B} Q^{\prime}{ }_{00} \gtreqless{ }_{B} Q^{\prime}{ }_{11}>{ }_{B} Q^{\prime}{ }_{10} ;{ }_{B} Q^{\prime}{ }_{01}>{ }_{B} Q^{\prime}{ }_{10} \text {, }
\end{aligned}
$$

etc.; the same pattern is necessarily observed for the $Q$ ratios. That is, households reporting intentions to buy a specific commodity and not purchasing are relatively likely to have reported buying intentions for other commodities that were also not purchased. Households purchasing a specific commodity without having reported buying intentions are apt to have purchased other items without having reported intentions to buy them either. And households whose intentions to buy (or not to buy) a specific commodity corresponded to their actions, show ratios between those for the other two groups.

These data would be inconsistent with the proposition that buying intentions reflect purchase probability if it could be assumed that the purchase probabilities for commodities $\mathrm{B}, \mathrm{C}, \ldots, \mathrm{N}$, holding constant 
TABLE B-4

Test of Substitution and Complementarity in Buying Intentions ${ }^{n}$ and Purchases

\begin{tabular}{|c|c|c|c|c|c|c|c|c|}
\hline \multirow{2}{*}{$\begin{array}{c}\text { Commodity by Which } \\
\text { Classified }\end{array}$} & \multicolumn{8}{|c|}{ Household Types ${ }^{\mathrm{b}}$} \\
\hline & $Q_{11}$ & $Q_{10}$ & $Q_{01}$ & $Q_{00}$ & $Q_{11}^{\prime}$ & $Q^{\prime}{ }_{10}$ & $Q_{01}^{\prime}$ & $Q_{00}^{\prime}$ \\
\hline Room air conditioner & 1.289 & 0.719 & 2.569 & 1.463 & 1.490 & 1.080 & 1.697 & 1.463 \\
\hline House air conditioner & 1.048 & 0.607 & 2.250 & 1.702 & 1.069 & 0.843 & 1.818 & 1.10 \\
\hline Automobile & 1.070 & 0.170 & 7.643 & 1.251 & 。 & 。 & ○ & c \\
\hline Movie camera & 1.536 & 0.882 & 2.667 & 1.400 & 2.363 & 1.617 & 1.795 & 1.400 \\
\hline Carpets and rugs & 1.219 & 0.529 & 3.176 & 1.649 & 1.331 & 0.756 & 2.171 & 1.649 \\
\hline Clothes dryer & 1.211 & 0.552 & 3.007 & 1.793 & 1.289 & 0.776 & 2.184 & 1.793 \\
\hline Dishwasher & 1.056 & 0.417 & 3.163 & 1.456 & 1.070 & 0.541 & 2.459 & 1.456 \\
\hline Food freezer & 1.594 & 0.601 & 3.527 & 1.404 & 2.267 & 0.807 & 2.432 & 1.40 \\
\hline Furniture & 1.240 & 0.485 & 3.531 & 1.468 & 1.387 & 0.781 & 2.297 & 1.46 \\
\hline Garbage disposal unit & 1.067 & 0.388 & 2.586 & 1.516 & 1.083 & 0.509 & 2.040 & 1.51 \\
\hline High-fidelity equipment & 1.287 & 0.533 & 3.146 & 1.827 & 1.625 & 0.875 & 2.013 & 1.827 \\
\hline Home heating system & 0.944 & 0.300 & 2.260 & 1.444 & 0.927 & 0.404 & 1.661 & 1.444 \\
\hline Range & 0.964 & 0.363 & 2.697 & 1.511 & 0.953 & 0.470 & 2.059 & 1.511 \\
\hline Refrigerator & 0.996 & 0.387 & 2.946 & 1.625 & 0.994 & 0.514 & 2.155 & 1.62 \\
\hline Washing machine & 1.301 & 0.500 & 2.863 & 1.496 & 1.460 & 0.713 & 1.973 & 1.496 \\
\hline Television set & 1.097 & 0.514 & 2.686 & 1.453 & 1.161 & 0.782 & 1.814 & 1.453 \\
\hline
\end{tabular}

Source: Basic data from Consumer Purchase Study, NBER.

a The question asked about intentions to buy within six months.

${ }^{b} Q_{11}$; Ratio of total purchases to total buying intentions for households that intended to buy and bought the commodity listed in the stub, including purchases of and intentions to buy the commodity itself.

$Q_{10}$; Same as $Q_{11}$, for households that intended to buy but did not buy the commodity listed in the stub.

$Q_{01}$; Same as $Q_{11}$, for households that did not intend to buy but bought the commodity listed in the stub.

$Q_{00}$; Same as $Q_{11}$, for households that neither intended to buy nor bought the commodity listed.

$Q^{\prime}{ }_{11}$; Ratio of total purchases to total buying intentions for households that intended to buy and bought the commodity listed in the stub, excluding purchases of and intentions to buy the commodity itself.

$Q^{\prime}{ }_{10}$; Same as $Q^{\prime}{ }_{11}$, for households that intended to buy but did not buy the commodity listed.

$Q^{\prime}{ }_{01}$; Same as $Q^{\prime}{ }_{11}$, for households that did not intend to buy but bought the commodity listed.

$Q^{\prime}{ }_{00}$; Same as $Q^{\prime}{ }_{11}$, for households that neither planned to buy nor bought the commodity listed.

- The $Q^{\prime}$ ratios for automobiles could not be computed without price weights for the automobiles; since the weights could not be obtained for this tabulation, only $Q$ ratios are shown.

intentions to buy $\mathrm{B}, \mathrm{C}, \ldots, \mathrm{N}$, are not correlated with the probability of purchasing A, holding constant intentions to buy A. Since this assumption cannot be tested, the results are not inconsistent with the probability hypothesis. Moreover, within the framework of the probability model, the observed results can be explained by a combination of response bias, as 
discussed earlier in this chapter, and the influence of unforeseen events. Perennial optimists would tend to be found in the 10 category, and would depress the $Q^{\prime}$ ratio for that group, while perennial pessimists would gravitate to the 01 category, increasing the $Q^{\prime}$ ratio for that group. Similarly, households that experience favorable unforeseen events would consistently wind up in the 01 category, since they are apt to buy more than anticipated; those experiencing the reverse are apt to wind up in the 10 category, since they are apt to buy less than anticipated.

Although the $Q$ or $Q^{\prime}$ ratios vary substantially when different commodities are used as the basis for classification, these variations do not appear to be related to any characteristic of the commodities-with the possible exception of home ownership. Items such as refrigerators behave much like dishwashers or garbage disposal units; consequently, the fraction of owners in the sample seems to make little difference to the substitution effect. However, items that would generally be purchased only by home owners - range, refrigerator, garbage disposal unit, dishwasher, etc.-show a stronger tendency toward complementarity than commodities that might be purchased by either owners or renters. For items that would be predominantly bought by owners the pattern in the $Q^{\prime}$ ratios is fairly consistent:

$$
\begin{aligned}
& Q^{\prime}{ }_{11} \sim 1.0 \\
& Q^{\prime}{ }_{10} \sim 0.5 \\
& Q^{\prime}{ }_{01} \sim 2.0 \\
& Q^{\prime}{ }_{00} \sim 1.5
\end{aligned}
$$

The explanation may be that intentions and purchases for these items are closely associated with house-buying intentions and purchases. A household intending to buy and buying a house or intending and carrying out kitchen modernization presumably reported intentions to buy and subsequently purchased a number of the individual commodities on the above list; this factor might explain the tendency of the $Q^{\prime}{ }_{11}$ ratio to approach unity. Similarly, if a household intended to buy a house but did not purchase, its intentions to buy many household durables would not be fulfilled; classifying by one of these durables, households intending to buy some item but not purchasing would have reported intentions to buy many other items but would not have purchased them either. The reverse would be true for households that had not intended to buy a house but did so. ${ }^{4}$

4 There is some evidence of a positive substitution effect within the classification scheme used in Table 22. Although households that both intended to buy and purchased a commodity are likely to show a ratio of aggregate purchases to intentions of 
On the whole, the results seem to indicate that failure to fulfill a specific intention to buy (or not to buy) is less generally associated with a change in priority vis-à-vis particular items on the above commodity list than with a change in priority vis-à-vis the entire list relative to other categories of expenditure (or saving). The results thus suggest that households are apt to purchase household durable goods in clusters, and that factors leading to the purchase of one item will frequently result in the purchase of others at the same time.

about unity, they did not purchase every item they intended to. One can find substantial numbers of unintended purchases balanced by intentions that were not carried out. Consequently, another way of interpreting these results is that unintended purchases approximately balance unfulfilled intentions in the 11 group; unfulfilled intentions are much greater than unintended purchases in the 10 group; and the reve rse is true for the 01 category. In the 00 group unintended purchases are customarily greater than unfulfilled intentions because of the characteristics of the intentions question. 